\title{
Diagnostic management of suspected metastatic thyroid carcinoma: clinical value of octreotide scintigraphy in patients with negative high-dose radioiodine scans
}

\author{
Francesco Giammarile, Claire Houzard ${ }^{1}$, Claire Bournaud ${ }^{2}$, Zakia Hafdi ${ }^{1}$, Geneviève Sassolas ${ }^{1}$ and \\ Françoise Borson-Chazot ${ }^{1}$ \\ Nuclear Medicine Department, Centre Léon Bérard, Lyon, France, ${ }^{1}$ Nuclear Medicine Department, Hôpital Neuro-cardiologique, Lyon, France and \\ ${ }^{2}$ Department of Endocrinology, Hôpital Lyon-Sud, France \\ (Correspondence should be addressed to F Giammarile, Centre Léon Bérard, Nuclear Medicine Department, 28, rue Laennec 69373 Lyon cedex O8, \\ France; Email: giammari@lyon.fnclcc.fr)
}

\begin{abstract}
Objectives: Somatostatin receptor scintigraphy (SRS) with ${ }^{111}$ In-octreotide has been suggested as a potential tool for the detection of recurrent or metastatic differentiated thyroid cancer when no radioiodine uptake can be demonstrated in tumour sites. However, there is no consensus concerning the performance and clinical impact of this examination in such instances.

Design and methods: A prospective study was undertaken to evaluate SRS in 43 patients (18 men, 25 women) with papillary $(n=20)$, follicular $(n=9)$, insular $(n=6)$ and oncocytic $(n=8)$ thyroid carcinomas with elevated serum thyroglobulin $(\mathrm{Tg})$ levels and no detected radioiodine uptake. Results: Evaluation criteria were interpreted in terms of an assumed presence of tumoural tissue. Sensitivity of SRS was 51\%, clearly lower than that of conventional imaging procedures, and of positron emission tomography using $\left[{ }^{18} \mathrm{~F}\right]$-2-fluoro-2-deoxy-D-glucose, performed in a subset of 27 patients. In addition, we observed two false-positive foci of uptake of octreotide that corresponded to inflammatory pulmonary sites. The sensitivity was higher in patients with $\mathrm{Tg}$ levels greater than $50 \mu \mathrm{g} / \mathrm{l}(76 \%)$ for detecting mediastinal lesions (93\%), and in patients with oncocytic cancer (88\%). Finally, SRS changed treatment strategy in four patients.

Conclusion: In differentiated thyroid cancer, SRS is a moderately sensitive method for the detection of lesions unable to concentrate iodine and appears useful only in patients with very high Tg levels or in oncocytic cancer.
\end{abstract}

European Journal of Endocrinology 150 277-283

\section{Introduction}

After total thyroidectomy and radioiodine ablation for differentiated thyroid cancer, it may be difficult to identify the recurrence site in patients with persistently elevated serum thyroglobulin $(\mathrm{Tg})$ and negative radioiodine (iodine-131) whole-body scans (WBSs) performed with a high activity $(1-3)$. The loss of ability to trap iodine while retaining the ability to secrete $\mathrm{Tg}$ is frequent in patients with poorly differentiated follicular and oncocytic carcinomas (3, 4). In such instances, an improved detection of lesions is likely to lead to better clinical management, including a more appropriate selection of patients who might benefit from surgery.

Conventional imaging procedures (CIPs), such as ultrasound (US) of the neck and abdomen, spiral computed tomography (CT) and/or magnetic resonance imaging (MRI) and bone scintigraphy, are effective in localizing recurrences of differentiated thyroid cancer.
However, the anatomical imaging modalities may be poorly specific, particularly in cases with altered anatomy (due to previous surgical explorations) or in certain sites such as the mediastinum, and also have a limited field of view (4).

Scintigraphic imaging modalities offer the possibility of whole-body evaluation, allowing an increase over the sensitivity of CIPs, by indicating on which anatomical areas these morphological examinations should be focused. Several radiopharmaceuticals, such as thallium-201 chloride and technetium-99m-labelled isonitrile compounds (sestamibi or tetrafosmin), have been proposed in patients with thyroid carcinoma, but results were not completely satisfactory $(5,6)$. Positron emission tomography (PET) using $\left[{ }^{18} \mathrm{~F}\right]$-2-fluoro2-deoxy-D-glucose (FDG) is a promising technique for the detection of recurrences of differentiated thyroid cancer, especially in cases with no detected iodine uptake, but the method is expensive and may be not readily available $(7,8)$. 
For over a decade, somatostatin receptor scintigraphy (SRS) with ${ }^{111}$ In-DTPA-D-Phe-octreotide (Octreoscan; Mallinckrodt, Petten, The Netherlands) has been widely used as a diagnostic agent, particularly to image neuroendocrine tumours (9). Since thyroid tumour cells express somatostatin receptors, SRS has been proposed as a potential tool for the diagnosis of recurrences in differentiated thyroid carcinomas (10). However, conflicting results have been reported, with sensitivities ranging from 25 to $75 \%$, depending on patient selection and positivity criteria $(10-12)$.

This prospective study was undertaken in 43 patients with differentiated thyroid carcinoma, elevated serum $\mathrm{Tg}$ levels and no detected radioiodine uptake on WBSs, to evaluate the performances of SRS by reference to CIPs and clinical follow-up. In 27 patients, these results were compared with those of PET-FDG to assess the respective interest of each of these tests.

\section{Materials and methods}

\section{Patients}

Forty-three consecutive patients with differentiated thyroid cancer (18 males, 25 females; age range: $22-$ 70 years; mean age: 49 years) were prospectively studied (Table 1). Total thyroidectomy had been performed in all cases, between 1 and 23 years previously. The histopathological analysis revealed 20 papillary, 9 follicular, 6 insular and 8 oncocytic (Hürthle-cell) thyroid carcinomas. The disease stage at diagnosis was defined according to the National Thyroid Cancer Treatment Cooperative study staging system (13).

Surgical treatment was followed by iodine-131 ablative therapy $(2-4 \mathrm{GBq}$, depending on the radioiodine uptake in the thyroid bed). During follow-up, the patients received between one and eight therapeutic doses of iodine-131 (cumulative range $3.7-33.3 \mathrm{GBq}$, average dose $13.8 \mathrm{GBq}$ ) because of elevated Tg levels (means \pm S.D. $3114 \pm 10800 \mu \mathrm{g} / \mathrm{l}$, range: $22-70119 \mu \mathrm{g} / \mathrm{l})$. These treatments resulted in the disappearance of radioiodine uptake in neoplastic foci. However, the Tg level remained elevated (mean $758 \pm 1419 \mu \mathrm{g} / \mathrm{l}$, range: $0.7-5850 \mu \mathrm{g} / \mathrm{l}$, during levothyroxine treatment), with no anti-Tg antibody, suggesting the presence of active disease. The mean delay between the last radioiodine treatment and SRS was $21 \pm 28$ months (range 1 week to 10 years).

The study was approved by the local ethics committee, and was performed according to the Helsinki guidelines. Each patient signed informed written consent.

\section{CIPs}

Serum Tg and anti-Tg antibody were measured by an IRMA method at the time of WBS and on the day of SRS.
WBSs were routinely performed 3-4 days after a therapeutic dose of iodine-131 (1.9-5.6 GBq), following thyroid hormone withdrawal (thyrotrophin (TSH) level higher than $30 \mathrm{mU} / \mathrm{l}$ ), using a dual-head large-field-ofview gamma camera equipped with a high-energy collimator (Siemens Body Scan, Chicago, IL, USA).

CIPs first included chest X-rays and neck US. CT and/or MRI of the neck and chest (and occasionally the abdomen) were performed mostly when the two first examinations were negative or doubtful, and always in the case of unexpected SRS findings. ${ }^{99 \mathrm{~m}} \mathrm{Tc}-$ diphosphonate bone scintigraphy was performed in cases of clinically suspected bone metastases.

\section{PET-FDG acquisitions}

Examinations were performed in 27 fasting patients, mostly during levothyroxine suppression. Images were acquired $60 \mathrm{~min}$ after i.v. administration of $2 \mathrm{MBq} / \mathrm{kg}$ FDG, using a three-head large field-of-view gamma camera equipped with coincidence detection of $511 \mathrm{keV}$ annihilation quanta (IRIX; Philips Medical Systems, Cleveland, OH, USA). Three acquisitions of neck, chest and abdomen involved a $120^{\circ}$ rotation of each detector, with 60 steps of $20-25 \mathrm{~s}$, and the total scanning time was approximately $1.5 \mathrm{~h}$. The non-attenuated corrected images were reconstructed using the iterative reconstruction technique.

\section{SRS acquisitions}

Examinations were performed during TSH-suppressive levothyroxine therapy except in three cases (Table 1). Patients received an i.v. injection of $110 \mathrm{MBq}$ Octreoscan. A dual-head large-field-of-view gamma camera equipped with a medium-energy collimator (PRISM 2000; Philips Medical Systems) provided anterior and posterior images at 4,24 and, when necessary, $48 \mathrm{~h}$. Data acquisition was performed using an energy window setting at 172 and $247 \mathrm{keV}$, with $15 \%$ of window width. Total body images were obtained by scanning at $10 \mathrm{~cm} / \mathrm{min}$ while $10-\mathrm{min}$ spot-centred views on the cervico-thoracic region were also recorded. When useful, single photon emission computed tomography from relevant regions was performed at $24 \mathrm{~h}$ (60 projections of $40 \mathrm{~s}$ acquired over $180^{\circ}$ reconstructed by filtered back-projection).

\section{Image interpretations}

All scintigraphic images were visually analysed by at least two experienced nuclear physicians blinded to the clinical situation and the consensus was reported in the clinical record. A focus of increased abnormal uptake was interpreted as a pathological site. The regions of uptake were divided into five areas: neck, lung, mediastinum, bone and other (including liver). Lesions were arbitrarily classified as multiple if more 
Table 1 Patient characteristics and results.

\begin{tabular}{|c|c|c|c|c|c|c|c|c|c|}
\hline $\begin{array}{l}\text { Patient } \\
\text { no. }\end{array}$ & Gender & $\begin{array}{c}\text { Age } \\
\text { (years) }\end{array}$ & Histology & $\operatorname{Tg}$ & TSH & CIP & SRS & Vf & Tm \\
\hline 1 & M & 48 & I & 12.5 & U & $3 \operatorname{cer}(\mathrm{TP})$ & $0 \operatorname{cer}(\mathrm{FN})$ & B & Survey \\
\hline 2 & M & 50 & $P$ & 2.1 & U & $0(\mathrm{FN})$ & $0(\mathrm{FN})$ & $\mathrm{F}$ & Survey \\
\hline 3 & $\mathrm{~F}$ & 24 & $\mathrm{P}$ & 5.3 & U & $2 \operatorname{cer}(\mathrm{TP})$ & $0 \operatorname{cer}^{\prime}(\mathrm{FN})$ & $\mathrm{H}$ & Surgery \\
\hline 4 & $\mathrm{~F}$ & 27 & $P$ & 1.4 & $U$ & $0(\mathrm{FN})$ & $0(\mathrm{FN})$ & $\mathrm{F}$ & Survey \\
\hline 5 & $\mathrm{~F}$ & 22 & $\mathrm{P}$ & 7.4 & $U$ & 0 (FN) & $0(\mathrm{FN})$ & $\mathrm{F}$ & Survey \\
\hline 6 & $\mathrm{~F}$ & 24 & $P$ & 0.7 & U & $4 \operatorname{cer}(\mathrm{TP})$ & $0 \operatorname{cer}(\mathrm{FN})$ & $\mathrm{H}$ & Surgery \\
\hline 7 & M & 29 & $\mathrm{P}$ & 6 & U & $0(\mathrm{FN})$ & $0(\mathrm{FN})$ & $\mathrm{F}$ & Survey \\
\hline 8 & $\mathrm{~F}$ & 31 & $P$ & 13.4 & U & 1 cer (TP) & $0 \operatorname{cer}(\mathrm{FN})$ & B & Survey \\
\hline 9 & M & 45 & $P$ & 13.6 & $U$ & 1 cer (TP) & 1 cer (TP) & $\mathrm{H}$ & Surgery \\
\hline 10 & M & 52 & I & 7 & U & $\begin{array}{l}1 \text { cer (TP) } \\
1 \text { med (TP) }\end{array}$ & $\begin{array}{l}0 \text { cer (FN) } \\
0 \text { med (FN) }\end{array}$ & $\begin{array}{l}\mathrm{B} \\
\mathrm{F}\end{array}$ & Radiotherapy \\
\hline 11 & M & 67 & $P$ & 2.4 & U & $\begin{array}{l}1 \text { cer (TP) } \\
1 \text { med (TP) }\end{array}$ & $\begin{array}{l}1 \text { cer (TP) } \\
1 \text { med (TP) }\end{array}$ & $\begin{array}{l}\mathrm{B} \\
\mathrm{F}\end{array}$ & Survey \\
\hline 12 & $\mathrm{~F}$ & 27 & $\mathrm{P}$ & 3 & U & $0(\mathrm{FN})$ & $0(\mathrm{FN})$ & $\mathrm{F}$ & Survey \\
\hline 13 & $\mathrm{~F}$ & 51 & $\mathrm{~F} \mathrm{pd}$ & 17 & $U$ & 1 pulm (TP) & 0 pulm (FN) & $\mathrm{F}$ & Surgery \\
\hline 14 & $\mathrm{~F}$ & 67 & $\mathrm{H}$ & 23.1 & U & $1 \operatorname{cer}(\mathrm{TP})$ & 1 cer (TP) & $\mathrm{H}$ & Surgery \\
\hline 15 & $\mathrm{~F}$ & 34 & $\mathrm{~F} \mathrm{pd}$ & 38 & U & 1 pulm (TP) & 0 pulm (FN) & $\mathrm{H}$ & Surgery \\
\hline 16 & M & 50 & $\mathrm{P}$ & 29 & U & 3 pulm (TP) & 0 pulm (FN) & $\mathrm{F}$ & Survey \\
\hline 17 & M & 67 & $P$ & 40 & $U$ & $0(\mathrm{FN})$ & $0(\mathrm{FN})$ & $\mathrm{F}$ & Survey \\
\hline 18 & M & 66 & $P$ & 38 & $U$ & $1 \operatorname{cer}(\mathrm{TP})$ & $1 \operatorname{cer}(\mathrm{TP})$ & $\mathrm{H}$ & Surgery \\
\hline 19 & M & 46 & I & 131 & $U$ & 0 med $(\mathrm{FN})$ & 3 med (TP) & $\mathrm{H}$ & Surgery \\
\hline 20 & M & 60 & $\mathrm{H}$ & 150 & $U$ & $\begin{array}{l}\text { M pulm (TP) } \\
0 \text { med (FN ?), } \\
1 \text { bone (TP) }\end{array}$ & $\begin{array}{l}\text { M pulm (TP) } \\
2 \text { med (TP ?), } 0 \text { bone } \\
\text { (FN) }\end{array}$ & $\begin{array}{l}\mathrm{H} \\
\mathrm{F}\end{array}$ & Surgery/radiotherapy \\
\hline 21 & $\mathrm{~F}$ & 45 & $\mathrm{H}$ & 96 & $U$ & 1 pulm (TP) 1 med (TP) & $\begin{array}{l}1 \text { pulm (TP) } 1 \text { med } \\
\text { (TP) }\end{array}$ & $\mathrm{H}$ & Surgery \\
\hline 22 & M & 44 & $P$ & 66 & 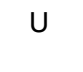 & 1 cer (TP), M pulm (TP) & $\begin{array}{l}0 \text { cer (FN), } 2 \text { pulm } \\
\text { (TP) }\end{array}$ & $\mathrm{H}$ & Surgery/radiotherapy \\
\hline & & & & & & $\begin{array}{l}0 \text { med (FN ?), } 0 \text { abd } \\
\text { (FN ?) }\end{array}$ & $\begin{array}{l}3 \text { med (TP ?), } 1 \text { abd } \\
\text { (TP ?) }\end{array}$ & $\mathrm{F}$ & \\
\hline 23 & $\mathrm{~F}$ & 62 & I & 56 & $U$ & $0(\mathrm{FN})$ & 1 pulm (FP) & $\mathrm{H}$ & Survey \\
\hline 24 & $\mathrm{~F}$ & 63 & $\mathrm{H}$ & 180 & U & 0 med $(F N)$ & 1 med (TP) & $\mathrm{H}$ & Surgery \\
\hline 25 & $\mathrm{~F}$ & 29 & $\mathrm{~F}$ & 187 & U & 2 cer (T'P) & $0 \operatorname{cer}(\mathrm{FN})^{\prime}$ & $\mathrm{H}$ & Surgery \\
\hline 26 & $\mathrm{~F}$ & 63 & $\mathrm{H}$ & 255 & $U$ & $0(\mathrm{FN})$ & 1 pulm (FP) & $\mathrm{F}$ & Survey \\
\hline 27 & $\mathrm{~F}$ & 41 & $P$ & 171 & 58.2 & $0(\mathrm{FN})$ & $0(\mathrm{FN})$ & $\mathrm{F}$ & Survey \\
\hline 28 & $\mathrm{~F}$ & 59 & $\mathrm{P}$ & 176 & $U$ & $M(p u l m)(T P)$ & 0 pulm (FN) & $\mathrm{H}$ & Surgery \\
\hline 29 & $\mathrm{~F}$ & 53 & $P$ & 5850 & 38 & 2 med (TP) & 1 med (TP) & $\mathrm{H}$ & Surgery \\
\hline 30 & M & 62 & $\mathrm{P}$ & 981 & $\mathrm{U}$ & M pulm (TP) & 3 pulm (TP) & $\mathrm{F}$ & Redifferentiation \\
\hline 31 & $\mathrm{~F}$ & 53 & $\mathrm{~F}$ & 609 & $\mathrm{U}$ & 1 bone (TP) & 0 bone (FN) & $\mathrm{F}$ & Radiotherapy \\
\hline 32 & M & 48 & I & 2205 & $U$ & $\begin{array}{l}0 \text { cer (FN), } 3 \text { med (TP), } \\
\text { M pulm (TP), } \\
\text { M bone (TP) }\end{array}$ & $\begin{array}{l}1 \text { cer (TP), } 3 \text { med } \\
\text { (TP), } 2 \text { pulm (TP), } \\
0 \text { bone (FN) }\end{array}$ & $\mathrm{F}$ & Redifferentiation \\
\hline 33 & M & 53 & $\mathrm{H}$ & 2331 & $U$ & 1 med (TP), M pulm (TP) & 2 med (TP), 0 pulm (FN) & $\mathrm{H}$ & Surgery/radiotherapy \\
\hline 34 & $\mathrm{~F}$ & 49 & $\mathrm{P}$ & 775 & $U$ & $\begin{array}{l}\text { M pulm (TP) } \\
0 \text { med (FN ?), } 3 \text { bone (TP) }\end{array}$ & $\begin{array}{l}\text { M pulm (TP) } \\
1 \text { med (TP ?), } 3 \text { bone (TP) }\end{array}$ & $\begin{array}{l}\mathrm{H} \\
\mathrm{F}\end{array}$ & Surgery \\
\hline 35 & M & 47 & $\mathrm{H}$ & 861 & $\mathrm{U}$ & $\begin{array}{l}2 \text { cer (TP) } \\
0 \text { med (FN) }\end{array}$ & $\begin{array}{l}0 \text { cer (FN) } \\
2 \text { med (TP) }\end{array}$ & $\begin{array}{l}\mathrm{B} \\
\mathrm{F}\end{array}$ & Surgery \\
\hline 36 & M & 70 & $\mathrm{~F} \mathrm{pd}$ & 1964 & $\mathrm{U}$ & $0(\mathrm{FN})$ & $0(\mathrm{FN})$ & $\mathrm{F}$ & Survey \\
\hline 37 & $\mathrm{~F}$ & 58 & $\mathrm{Fpd}$ & 1755 & $U$ & $\begin{array}{l}\text { M pulm (TP) } 1 \text { med (TP) } \\
1 \text { abd (TP) }\end{array}$ & $\begin{array}{l}1 \text { pulm (TP) } 2 \text { med (TP) } \\
0 \text { abd (FN) }\end{array}$ & $\mathrm{F}$ & Redifferentiation \\
\hline 38 & $\mathrm{~F}$ & 57 & $P$ & 323 & 69 & $\begin{array}{l}4 \text { cer (TP) } \\
0 \text { med (FN), M pulm (TP) } \\
1 \text { abd (TP) }\end{array}$ & $\begin{array}{l}4 \text { cer (TP) } \\
3 \text { med (TP), } 0 \text { pulm (FN) } \\
1 \text { abd (TP) }\end{array}$ & $\begin{array}{l}\mathrm{H} \\
\mathrm{H} \\
\mathrm{F}\end{array}$ & Surgery/radiotherapy \\
\hline 39 & $\mathrm{~F}$ & 63 & $\mathrm{~F}$ & 800 & $\mathrm{U}$ & 1 med (TP), M pulm (TP) & 2 med (TP), 1 pulm (TP) & $\mathrm{H}$ & Surgery \\
\hline 40 & $\mathrm{~F}$ & 50 & $\mathrm{H}$ & 4882 & U & M pulm (TP) & M pulm (TP) & $\mathrm{H}$ & Surgery \\
\hline 41 & $\mathrm{~F}$ & 62 & $\mathrm{~F}$ & 5250 & $\mathrm{U}$ & 1 med (TP) & 1 med (TP) & $\mathrm{H}$ & Surgery/radiotherapy \\
\hline 42 & $\mathrm{~F}$ & 35 & I & 1440 & $U$ & 3 med (TP), M pulm (TP) & 1 med (TP), 2 pulm (TP) & $\mathrm{H}$ & Surgery \\
\hline 43 & M & 60 & $\mathrm{~F}$ & 850 & $\mathrm{U}$ & 0 abd (FN) & $1 \mathrm{abd}(\mathrm{TP})$ & $\mathrm{F}$ & Metabolic radiotherapy \\
\hline
\end{tabular}

$\mathrm{Tg}=\mathrm{Tg}$ on the day of SRS exam (in $\mu \mathrm{g} / \mathrm{l}$ ).

$\mathrm{TSH}=\mathrm{TSH}$ on the day of SRS exam (in $\mathrm{U} / \mathrm{I}$ ).

$\mathrm{TP}=$ true positive, $\mathrm{FN}=$ false negative, $\mathrm{FP}=$ false positive.

$\mathrm{V} f=$ verification by cytology $(B)$, histology $(H)$ or follow-up $(F)$.

$\mathrm{Tm}=$ Therapeutic management (in italic: SRS findings changed management).

cer $=$ cervical, med $=$ mediastinum, pulm $=$ pulmonary, abd $=$ abdominal.

$\mathrm{U}=$ undetected, $\mathrm{P}=$ papillary, $\mathrm{F}=$ follicular, $\mathrm{pd}=$ poorly differentiated, $\mathrm{I}=$ insular, $\mathrm{O}=$ oxclocytic, $\mathrm{M}=$ multiple (more than four sites). 
than four sites were detected. Overall, a positive examination in a patient was defined by at least one abnormal uptake in one site and results were expressed in terms of both positive patients and tumour sites.

The scintigraphic results were retrospectively compared with CIPs, obtained within 6 months. If necessary, the CIP examinations were repeated with the radiologist aware of PET-FDG and SRS findings.

\section{Evaluation and statistical analysis}

Since no single imaging modality is recognized as the gold standard to indicate the presence or absence of thyroid cancer, the evaluation criteria were defined in terms of assumed presence of tumoural tissue (because of persistent Tg levels) and not on the basis of CIP findings. Verification of a true-positive finding was then achieved by positive cytology (performed by ultrasonography-guided fine-needle aspiration biopsy) or histology (performed after surgery) in 27 patients. In the other 16 patients, the final decision took into account the clinical outcome and biological follow-up, together with all imaging findings.

Lesion detectability in CIPs and SRSs are expressed as the percentage of patients with positive rates and compared using the $\chi^{2}$ test. The threshold of significance was set at 0.05 .

\section{Results}

\section{Overall sensitivity (Table 1)}

In eight patients, no tumour site could be detected with any of the available methods, including PET-FDG. In two patients, SRS revealed lung uptake that proved to be related to tuberculosis (no. 23) or sarcoidosis (no. 26).

The remaining 33 patients presented with unequivocal metastases, local recurrence or residual tumour, shown by at least one imaging modality and then confirmed either directly (histopathologically) or indirectly (by clinical follow-up). CIP was unequivocally positive in 30 patients $(70 \%)$, and was the only positive test in five of them. SRS was positive in 22 patients $(51 \%)$, and was the only positive test in three of them. PET-FDG was performed in 27 patients, belonging to a larger series of patients whose results have been previously reported (14). The examination was unequivocally positive in 16 patients, and was the only positive test in one patient.

\section{Sensitivity according to tumour site (Table 2)}

In the 34 patients in whom an unequivocal lesion was detected, the following tumour sites were discovered: cervical (15 patients), mediastinal (18 patients), pulmonary (17 patients), skeletal (5 patients), and abdominal (4 patients).
Table 2 Site sensitivity.

\begin{tabular}{|c|c|c|c|c|c|c|c|c|}
\hline \multirow[b]{2}{*}{ Site } & \multicolumn{3}{|c|}{ CIP } & \multicolumn{5}{|c|}{ SRS } \\
\hline & TP & FN & $\mathrm{Se}$ & TP & FN & $\mathrm{Se}$ & $?$ & FP \\
\hline Cervical & 13 & 1 & 93 & 6 & 8 & 43 & - & - \\
\hline Mediastinum & 10 & 8 & 56 & 14 & 1 & 93 & $2^{*}$ & - \\
\hline Pulmonary & 16 & 1 & 94 & 11 & 6 & 65 & - & 2 \\
\hline Bone & 4 & 0 & 100 & 1 & 3 & 25 & - & - \\
\hline Abdominal & 2 & 1 & 67 & 2 & 1 & 67 & $1 * \star$ & - \\
\hline Total & 45 & 11 & 80 & 34 & 19 & 64 & 3 & 2 \\
\hline
\end{tabular}

$\mathrm{TP}=$ true positive, $\mathrm{FN}=$ false negative, $\mathrm{Se}=$ sensitivity $(\%), ?=$ doubtful findings.

* Two lesions in mediastinal sites seen only on SRS.

** One hepatic lesion seen only on SRS.

SRS and CIP findings were comparable for abdominal sites, SRS and PET-FDG were superior to CIP for mediastinal sites, while CIP was superior in cervical, pulmonary and skeletal localization.

\section{Scintigraphic sensitivity according to $\mathbf{T g}$ (Table 3)}

To evaluate the relationship between serum Tg level and SRS sensitivity, the patients were divided into two groups, based on serum $\mathrm{Tg}$ levels obtained during levothyroxine therapy. In the first group ( $\mathrm{Tg}$ $<50 \mu \mathrm{g} / \mathrm{l})$, SRS was positive in only 3 of 18 patients, which is significantly lower than in the other group $(\mathrm{Tg}>50 \mu \mathrm{g} / \mathrm{l})(P<0.001)$. The lowest $\mathrm{Tg}$ with positive SRS findings was $2.4 \mu \mathrm{g} / \mathrm{l}$ and the highest Tg level with a negative SRS was $1964 \mu \mathrm{g} / \mathrm{l}$.

\section{Scintigraphic sensitivity according to histology and stage (Table 4)}

Significantly higher sensitivity was found in oncocytic carcinoma, where SRS was unequivocally positive in seven of eight patients $(88 \%)$. Of the 35 other patients, only $15(43 \%)$ showed SRS pathological localization. Similarly, there was a trend towards a lower number of positive SRSs in patients with initial stage I thyroid carcinoma $(22 \%)$.

\section{Patient management}

The SRS findings led to a change in the clinical management in four patients (namely, further surgery was decided or modified in patients no. 19, 24 and 35,

Table 3 Scintigraphic sensitivity according to Tg.

\begin{tabular}{lccc}
\hline & \multicolumn{3}{c}{ Tg level $(\mu \mathrm{g} / \mathrm{l})$} \\
\cline { 2 - 4 } & $<50$ & $>50$ & Total \\
\hline Positive & 3 & 19 & 22 \\
Total & 18 & 25 & 43 \\
Positive rate (\%) & 17 & 76 & 51 \\
\hline
\end{tabular}


Table 4 Scintigraphic sensitivity according to histology and stage.

\begin{tabular}{|c|c|c|c|c|c|c|c|c|c|}
\hline \multirow[b]{2}{*}{ SRS } & \multicolumn{4}{|c|}{ Histology } & \multicolumn{5}{|c|}{ Stage } \\
\hline & $\mathrm{P}$ & $\mathrm{F}$ & 1 & $\mathrm{O}$ & I & II & III & IV & $x$ \\
\hline Positive & 9 & 3 & 3 & 7 & 2 & 8 & 8 & 2 & 2 \\
\hline Total & 20 & 9 & 6 & 8 & 9 & 14 & 12 & 3 & 5 \\
\hline Positive rate (\%) & $(P+F+I)=43$ & & & 88 & 22 & & $(I I+I I I+I V)=62$ & & - \\
\hline
\end{tabular}

Histology: papillary $(P)$, follicular $(F)$, insular $(I)$ and oncocytic $(O)$ thyroid carcinomas.

and a metabolic radiation therapy with ${ }^{111}$ In-Octreoscan $(3.7 \mathrm{GBq})$ was decided in patient no. 43$)$.

The eight negative and the two false-positive SRS patients with persistently elevated $\mathrm{Tg}$ level were carefully followed up for 30 months (range 15-46), until the end of the study and remained without detected metastases.

\section{Discussion}

Human somatostatin receptors (hSSTR 1-5), which mediate the antiproliferative effects of somatostatin, are present in normal tissues and in several tumours, especially of neuroendocrine origin. Octreotide is a somatostatin analogue with high affinity for hSSTR2. Once labelled with ${ }^{111} \mathrm{In}$, the radiopharmaceutical has been widely used for imaging neuroendocrine tumours. In vitro studies recently revealed an expression of hSSTR2 in non-medullary differentiated thyroid carcinoma cell (15). Also there may be non-specific uptake in the intratumoural leukocytes or in the peritumoural and intratumoural blood vessels (15).

Earlier studies with SRS in patients with recurrent or metastatic differentiated thyroid cancer gave controversial results. While Baudin et al. (10) and Postema et al. (16) found a high sensitivity of more than $70 \%$, especially for mediastinal involvement, in the studies of Garin et al. (12) and Valli et al. (11) the sensitivity was low $(30 \%)$. These controversies may be partly attributed to patient selection or to the low number of cases (15).

The aim of our study was to evaluate the sensitivity and the clinical utility of SRS in the therapeutic management of patients with elevated serum $\mathrm{Tg}$ levels and no detected radioiodine uptake.

Due to elevated serum Tg levels, active tumour disease was assumed in all our patients, despite the fact that no lesion could be detected with any of the available methods, in ten cases. While histopathological investigations of all neck lesions were obtained, this was not always feasible for lung masses. We therefore admitted the clinical follow-up and a congruence of CIP and SRS findings as confirmed disease.

In these conditions, the overall sensitivity of SRS was only $51 \%$, but the influence of various factors should be evaluated.

First, the sensitivity of SRS varied with anatomical location. Mediastinal metastases were well detected by
SRS, for which its diagnostic accuracy was superior to that of CIP and PET-FDG. Conversely, false-negative results of SRS were mostly small neck or lung metastases.

Secondly, a significantly increased fraction of positive SRSs was found in patient with higher serum Tg levels. The 21 negative SRS patients had mean Tg levels of $171.5 \pm 434.7 \mu \mathrm{g} / \mathrm{l}$, while the 22 positive SRS patients had mean $\mathrm{Tg}$ levels of $1317.3 \pm 1782.1 \mu \mathrm{g} / \mathrm{l}$. The serum $\mathrm{Tg}$ level is related to tumour mass and our result may only reflect the increased sensitivity of SRS with increasing tumour mass (12). However, SRS examination was positive in a patient with a $\mathrm{Tg}$ level of $2.4 \mu \mathrm{g} / \mathrm{ml}$.

Thirdly, there was a trend towards a higher number of positive SRS findings in patients with higher initial stages. Similarly, the sensitivity of SRS was better in oncocytic thyroid carcinoma, since seven patients out of eight patients showed unequivocal pathological octreotide uptake. In these tumours, hSSTR 2 are generally overexpressed, whereas in the other differentiated thyroid carcinoma subtypes hSSTR2 are mainly expressed only at a late stage of the disease and receptor density is generally low $(11,17,18)$.

Fourthly, we observed two false-positive SRS examinations that corresponded to inflammatory pulmonary lesions. Also, since non-tumoural stroma cells may express somatostatin receptors, the lack of specificity of SRS should be kept in mind.

Finally, ten patients were negative and no lesion were detected during follow-up. This group of patients included seven papillary, one follicular (nearly differentiated), one insular, and one oncocytic thyroid carcinoma with various $\mathrm{Tg}$ levels (mean $60.2 \pm 91.2 \mu \mathrm{g} / \mathrm{l}$, range $1.4-256 \mu \mathrm{g} / \mathrm{ml}$ ).

The value of PET using FDG in the detection of thyroid cancer, first described in 1987 (19), has been further demonstrated in a number of prospective studies, with a high sensitivity of $85 \%$ (7). Generally, glucose metabolism correlates with malignancy grade and is increased in undifferentiated thyroid carcinoma, or in high-grade carcinomas of the well-differentiated type, which have lost their ability to concentrate iodine (20). Our results, obtained in 27 patients of the study, confirmed that PET-FDG may be useful for monitoring patients with elevated serum $\mathrm{Tg}$ levels and no detected radioiodine uptake on WBSs. 
The clinical impact of the early recognition of recurrent or metastatic thyroid cancer has not been precisely determined in patients with elevated serum $\mathrm{Tg}$ levels and no detected radioiodine uptake, since generally the therapeutic options in the these patients are limited (21). However, modifications of patient staging may suggest or contraindicate some therapeutic modalities. Moreover, beside tumour detection, SRS can be used to evaluate the possibility of a receptor-mediated radionuclide therapy in metastatic patients who cannot be treated by other modalities $(7,15,22,23)$.

In our study, in three patients SRS was the only diagnostic method showing unequivocal pathologic localization (mediastinal in two cases and abdominal in one case). After SRS, the clinical management changed in 4 of our 43 patients. In particular, the precise localization of the $\mathrm{Tg}$ production site allowed it to be subsequently totally removed by surgery in three patients, and one patient could benefit from a metabolic radiotherapy with high doses of ${ }^{111} \mathrm{In}$-Octreoscan.

\section{Conclusion}

Although SRS represents an effective imaging modality in a few patients with differentiated thyroid cancer, especially the oncocytic subtype, presenting with elevated serum $\mathrm{Tg}$ levels and no detected radioiodine uptake, we do not support the use of SRS as a firstchoice imaging modality in such instances. However, the documented uptake in tumour sites may suggest radiopeptide therapy when other therapeutic options are impossible. Furthermore, when PET-FDG is either unavailable or impracticable, SRS could provide evidence of the aggressiveness of the disease, mainly in patients with oncocytic thyroid carcinoma.

Whether or not the performance of the technique can be improved with new analogues, more specific for the sub-type(s) expressed in thyroid tumours, thus allowing both diagnosis and treatment, requires further study.

\section{Acknowledgements}

This study was supported by a grant from the Hospices Civils de Lyon (PHRC 1997 and 2000). The authors thank Dr Véronique Lapras and Dr Philippe Thiesse for accurate radiological explorations and advice.

\section{References}

1 Pineda JD, Lee T, Ain K, Reynolds JC \& Robbins J. Iodine-131 therapy for thyroid cancer patients with elevated thyroglobulin and negative diagnostic scan. Journal of Clinical Endocrinology and Metabolism $1995 \mathbf{8 0} 1488-1492$.

2 Maxon HR III \& Smith HS. Radioiodine-131 in the diagnosis and treatment of metastatic well differentiated thyroid cancer. Endocrinology and Metabolism Clinics of North America 199019 $685-718$.
3 Schlumberger MJ. Papillary and follicular thyroid carcinoma. New England Journal of Medicine 1998338 297-306.

4 Grunwald F, Briele B \& Biersack HJ. Non- ${ }^{131}$ I-scintigraphy in the treatment and follow-up of thyroid cancer. Quarterly Journal of Nuclear Medicine 199943 195-206.

5 Burman KD, Anderson JH, Wartofsky L, Mong DP \& Jelinek JJ. Management of patients with thyroid carcinoma: application of thallium-201 scintigraphy and magnetic resonance imaging. Journal of Nuclear Medicine 199031 1958-1964.

6 Dadparvar S, Chevres A, Tulchinsky M, Krishna-Badrinath L, Khan AS \& Slizofski WJ. Clinical utility of technetium-99m methoxisobutylisonitrile imaging in differentiated thyroid carcinoma: comparison with thallium-201 and iodine-131 Na scintigraphy, and serum thyroglobulin quantitation. European Journal of Nuclear Medicine 199522 1330-1338.

7 Grünwald F, Kalicke T, Feine U, Lietzenmayer R, Scheidhauer K, Dietlein M et al. Fluorine-18 fluorodeoxyglucose positron emission tomography in thyroid cancer: results of a multicentre study. European Journal of Nuclear Medicine 199926 1547-1552.

8 Helal BO, Merlet P, Toubert ME, Franc B, Schvartz C, GauthierKoelesnikov $\mathrm{H}$ et al. Clinical impact of (18)F-FDG PET in thyroid carcinoma patients with elevated thyroglobulin levels and negative (131)I scanning results after therapy. Journal of Nuclear Medicine $2001421464-1469$.

9 Krenning EP, Bakker WH, Breeman WA, Koper JW, Kooij PP, Ausema L et al. Localisation of endocrine-related tumours with radioiodinated analogue of somatostatin. Lancet $1989 \quad \mathbf{1}$ 242-244.

10 Baudin E, Schlumberger M, Lumbroso J, Travagli JP, Caillou B \& Parmentier C. Octreotide scintigraphy in patients with differentiated thyroid carcinoma: contribution for patients with negative radioiodine scan. Journal of Clinical Endocrinology and Metabolism $1996812541-2544$.

11 Valli N, Catargi B, Ronci N, Leccia F, Guyot M, Roger P et al. Evaluation of indium-111 pentetreotide somatostatin receptor scintigraphy to detect recurrent thyroid carcinoma in patients with negative radioiodine scintigraphy. Thyroid 19999 583-589.

12 Garin E, Devillers A, Le Cloirec J, Bernard AM, Lescouarch J, Herry JY et al. Use of indium-111 pentetreotide somatostatin receptor scintigraphy to detect recurrent thyroid carcinoma in patients without detectable iodine uptake. European Journal of Nuclear Medicine 199825 687-694.

13 Sherman SI, Brierley JD, Sperling M, Ain KB, Bigos ST, Cooper DS et al. Prospective multicenter study of thyroid carcinoma treatment: initial analysis of staging and outcome. National Thyroid Cancer Treatment Cooperative Study Registry Group. Cancer $1998831012-1021$.

14 Giammarile F, Hafdi Z, Bournaud C, Janier M, Houzard C, Desuzinges $\mathrm{C}$ et al. Is FDG PET useful in the management of suspected metastatic thyroid carcinoma in patients with no-detectable radioiodine uptake? European Journal of Endocrinology $2003 \mathbf{1 4 9}$ 293-300.

15 Görges R, Kahaly G, Muller-Brand J, Macke H, Roser HW \& Bockisch A. Radionuclide-labeled somatostatin analogues for diagnostic and therapeutic purposes in nonmedullary thyroid cancer. Thyroid $200111647-659$.

16 Postema PT, De Herder WW, Reubi JC, Oei HY, Kwekkeboom DJ, Bruining $\mathrm{HJ}$ et al. Somatostatin receptor scintigraphy in nonmedullary thyroid cancer. Digestion 199657 36-37.

17 Ain KB, Taylor KD, Tofiq S \& Venkataraman G. Somatostatin receptor subtype expression in human thyroid and thyroid carcinoma cell lines. Journal of Clinical Endocrinology and Metabolism 199782 1857-1862.

18 Tisell LE, Ahlman H, Wangberg B, Kolby L, Fjalling M, ForssellAronsson E et al. Expression of somatostatin receptors in oncocytic (Hürthle cell) neoplasia of the thyroid. British Journal of Cancer $1999791579-1582$.

19 Joensuu $\mathrm{H} \&$ Ahonen A. Imaging of metastases of thyroid carcinoma with fluorine-18 fluorodeoxyglucose. Journal of Nuclear Medicine 198728 910-914. 
20 Feine U, Lietzenmayer R, Hanke JP, Held J, Wohrle H \& Muller-Schauenburg W. Fluorine-18-FDG and iodine-131-iodide uptake in thyroid cancer. Journal of Nuclear Medicine 199637 1468-1472.

21 Lerch H, Schober O, Kuwert $T$ \& Saur HB. Survival of differentiated thyroid carcinoma studied in 500 patients. Journal of Clinical Oncology 199715 2067-2075.

22 Christian JA, Cook GJ \& Harmer C. Indium-111-labelled octreotide scintigraphy in the diagnosis and management of non-iodine avid metastatic carcinoma of the thyroid. British Journal of Cancer $200389258-261$.
23 Stokkel MP, Reigman HI, Verkooijen RB \& Smit JW. Indium-111octreotide scintigraphy in differentiated thyroid carcinoma metastases that do not respond to treatment with high-dose I-131. Journal of Cancer Research and Clinical Oncology 2003129 287-294.

Received 13 October 2003

Accepted 24 October 2003 